\title{
Assessment and validation of wildfire susceptibility and hazard in Portugal
}

\author{
J. C. Verde and J. L. Zêzere \\ RISKam - Research group on Environmental hazard and risk assessment and management, Geographical Research Centre, \\ University of Lisbon, Lisbon, Portugal
}

Received: 26 September 2009 - Revised: 21 January 2010 - Accepted: 25 January 2010 - Published: 16 March 2010

\begin{abstract}
A comprehensive methodology to assess forest fire susceptibility, that uses variables of strong spatial correlation, is presented and applied for the Portuguese mainland. Our study is based on a thirty-year chronological series of burnt areas. The first twenty years (1975-1994) are used for statistical modelling, and the last ten (1995-2004) are used for the independent validation of results. The wildfire affected areas are crossed with a set of independent layers that are assumed to be relevant wildfire conditioning factors: elevation, slope, land cover, rainfall and temperature. Moreover, the wildfire recurring pattern is also considered, as a proxy variable expressing the influence of human action in wildfire occurrence. A sensitivity analysis is performed to evaluate the weight of each individual theme within the susceptibility model. Validation of the wildfire susceptibility models is made through the computation of success rate and prediction rate curves. The results show that it is possible to have a good compromise between the number of variables within the model and the model predictive power. Additionally, it is shown that integration of climatic variables does not produce any relevant increase in the prediction capacity of wildfire susceptibility models. Finally, the prediction rate curves produced by the independent cross validation are used to assess the probabilistic wildfire hazard at a scenario basis, for the complete mainland Portuguese territory.
\end{abstract}

\section{Introduction}

Wildfires have destroyed, in the past few years, thousands of hectares in Portugal (e.g. over 425 thousand ha burnt in 2003 and over 300 thousand ha in 2005) stepping up as a major environmental problem in the country. Numbers have been

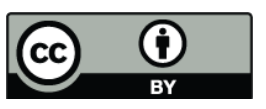

Correspondence to: J. C. Verde (verde@geographus.com) far more positive since 2006, but how they will evolve in the future is highly uncertain (Fig. 1). Between 1980 and 2007, wildfires have affected over 3 million ha in Portugal: that is equivalent to almost all of Belgium, one and half of Israel or twelve times the Luxembourg territory. Summed up, what was burnt in those 28 years is almost equivalent to the present day Portuguese forested areas.

Two thirds of Portugal is forested spaces, providing for paper, cork, furniture and many more products accounting for $3.2 \%$ of the Gross National Product (GNP), and 15 thousand jobs, in 2005. This data points to wildfires as a problem, not even accounting other environmental issues. Furthermore, the Portuguese forest was last evaluated at around 7750 million€. To sum it up, the problem is how to sustain $64 \%$, roughly two thirds, of the Portuguese territory.

Wildfires are not a Portuguese exclusive and several authors have dedicated their time investigating how to best model and achieve cartographic tools for wildfire susceptibility and hazard assessment, such as the work of Chuvieco and Congalton (1989), Viegas et al. (1999), Vasilakos et al. (2007), and Verde (2008) among others. Some attempts have been made to model susceptibility by means of different methods, like nearest-neighbourhood. Such is the case of Amatulli et al. (2007) who applied interpolation techniques to map lightning/human-caused wildfires, or Durão et al. (2010) whose work, dealing with the Canadian FWI system, tried to assess the probability of fire in a given region by running simulations. Apart from the somewhat static approach of susceptibility assessments, other authors have explored the correlations of wildfires and weather conditions, such as in Pereira et al. (2005), Trigo et al. (2006) and Le Page et al. (2008). Wildfire prevention is a vector for model development, driving efforts for a better prediction of those conditions that favour fire spread, or to allow for a quicker wildfire detection. The United States National Weather Service is running an experimental interface which divulges fire weather warnings, outlooks and danger

Published by Copernicus Publications on behalf of the European Geosciences Union. 


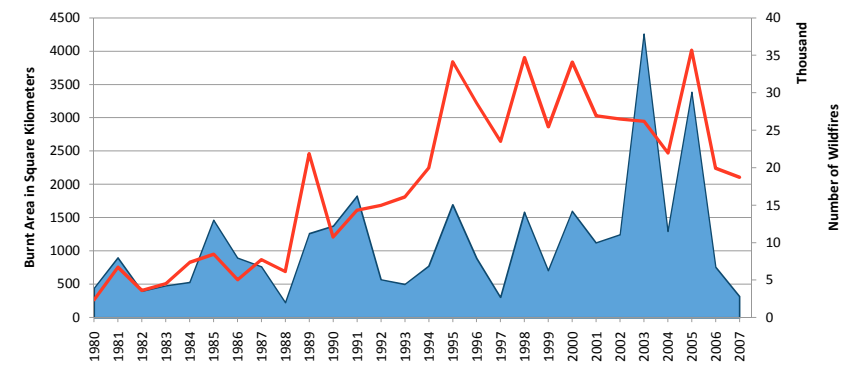

Fig. 1. Evolution of burnt area and number of wildfires in Portugal from 1980 to 2007.

ratings (NOAA, 2010), and while that information is for North America, a similar service, under the United Nations International Strategy for Disaster Reduction (UN-ISDR), provides a global early warning system for wildfires, whose objective is to "(...) provide a scientifically supported, systematic procedure for assessing current and future fire danger that can be applied from local to global scales. (...)" (GWFEWS, 2010). Other global modules have been developed under the UN-ISDR, such as the Lund-Potsdam-Jena Dynamic Global vegetation model, looking for interactions between vegetation and fire (GFMC, 2010). All these studies and approaches share a common goal, explicit or implicit: through a better knowledge of wildfire susceptibility, on land or atmospheric conditioning factors, reducing exposure and minimizing losses. The aforementioned studies have varying degrees of complexity, and many more authors have studied this subject, making it very difficult to refer them all. This paper focuses more on susceptibility as a property of the territory and less on wildfire dynamic patterns due to weather conditions, although correlations with rainfall and temperature are explored, to investigate model behaviour with similar variables as those used by other authors.

\section{The conceptual framework}

In Sect. 1, we have shown that the problem is how to sustain a large portion of the Portuguese territory. To do so, concepts must be clearly defined and understood, because actions might be taken to deal with the problem on the hazard level - through hazard reduction - or by risk mitigation on a broader sense.

A consensus regarding the concept of wildfire risk does not exist. Bachmann and Allgöwer (1999) have already addressed that issue, pointing out that "the somewhat inconsiderate use of the various terms "danger", "hazard", and "risk" may result in misunderstandings that can have fatal consequences" (op.cit., p. 1). Indeed, if a common understanding of what is hazard and what is risk does not exist, we might end up using products in an erroneous way: wildfire risk maps, containing financial data, cannot be read as direct

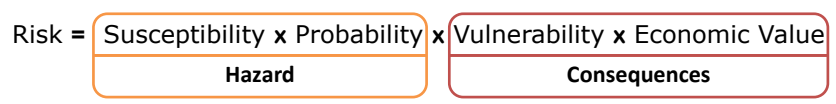

Fig. 2. Conceptual framework, based on Varnes (1984) and Bachmann and Allgöwer (1999).

indications of where a wildfire can grow faster and harder to extinguish due to increased susceptibility or recurrence patterns. If such a mistake happens at an operational level, where decisions must be made fast and accurately, consequences may be dire.

As the aforementioned authors pointed out, "the phenomenon fire has so many aspects as do people who are dealing with it (...) based on their primary interests, each of these "communities" has different notions of the term "wildfire risk" (Bachmann and Allgöwer, 1999, p. 1). The conceptual framework we adopt in this paper is the same framework widely applied to study other hazardous phenomena, like mass movements, floods or earthquakes, following the UNDRO (1979) and Varnes (1984) proposal and the risk definition given by Bachmann and Allgöwer (1999, p. 5): "the probability of a wildfire occuring at a specified location and under given circumstances and its expected outcome as defined by the impacts on the affected objects". We consider wildfire susceptibility the terrain propensity to suffer a wildfire or to support its spreading, given by the terrain's intrinsic characteristics (e.g., elevation, slope, vegetation cover). In addition, we consider wildfire hazard as the probability of a wildfire occurance associated with terrain susceptibility.

In this paper, we do not get into risk. Our study stops at hazard assessment. Figure 2 shows the adopted conceptual framework.

\section{Susceptibility assessment}

For susceptibility assessment, our model integrates some widely used variables in wildfire hazard modelling. The following variables were considered: elevation, slope, land cover, average annual rainfall, average number of days with minimum temperature $\geq 20^{\circ} \mathrm{C}$, and past burn scar mapping (which we transformed into simple probability). We have chosen to include those variables that relate to the fire triangle, air, heat and fuel, but also to the most prominent fire agent in Portugal: man. We did not consider variables that could be best used in dynamic mapping (e.g., wind speed and direction), mostly when fire is already progressing, as our purpose was to map susceptibility in the long term, as a property of the territory, as mentioned in Sect. 1. A sensitivity analysis was performed in order to assess the variable combination with the best prediction capacity. Figure 3 summarizes the adopted methodology from data capture to wildfire susceptibility and hazard evaluation. 


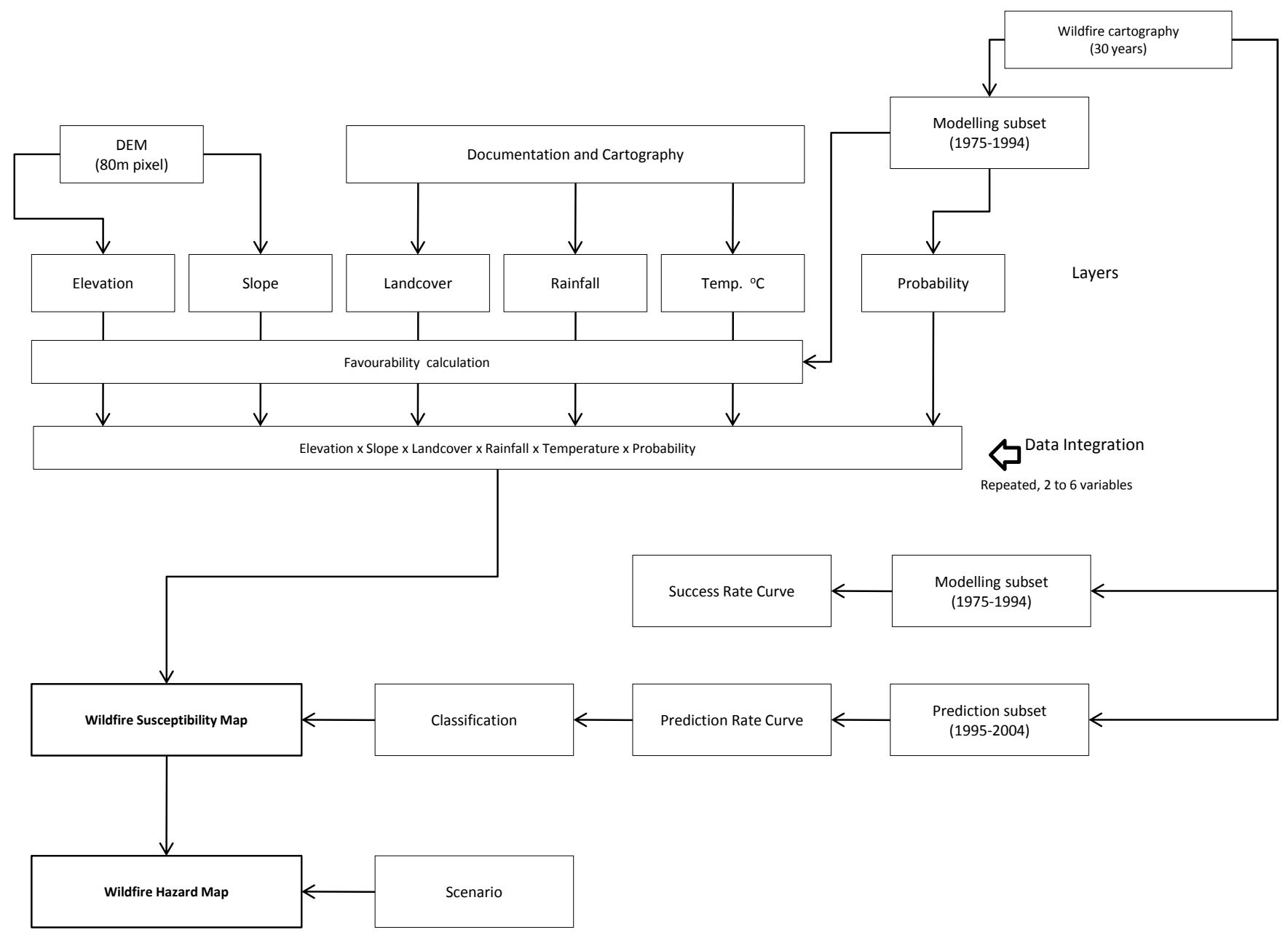

Fig. 3. General methodology from data sources and data integration, to susceptibility and hazard mapping.

\subsection{Data capture}

Elevation is one of the wildfire conditioning factors. Elevation "controls temperature and rainfall" (Ventura and Vasconcelos, 2006, p. 101-102), which will, in turn, influence the type and availability of fuel, as well as its humidity. Elevation is not homogeneous in Portugal, and the higher values are found in the central and northern part of the country (Fig. 4).

Influence of slope on fire progression is well known. The higher the slope, the faster fire progresses by heating of fuels uphill. Slope is also a factor that controls the wind speed (Macedo and Sardinha, 1993; Ferreira de Castro et al., 2003; Viegas, 2006). The spatial pattern of slope distribution in Portugal is similar to that of elevation (Fig. 5). The slope gradient is usually higher in the north and central part of the country.
The existence of wildfire susceptibility depends on susceptible territories, and it does not make any sense to assess wildfire susceptibility where wildfires cannot occur. Therefore, we have excluded from the land cover thematic layer (CORINE Land Cover 2000), all artificial areas, inland water bodies and ocean, corresponding to levels 1, 4 and 5 (Fig. 6).

The selection of the appropriate meteorological parameters to integrate wildfire susceptibility models is a significant issue. In Portugal, according to Pereira et al. (2006), "rainfall between January and April shows a slight positive correlation with burnt areas, possibly because it favours the growth of fine fuels (...) to burn during the summer". On the other hand, "there is a negative correlation (...) between the burnt area and rainfall during the month of May" (op.cit, p. 149) which results in higher humidity levels on those fine fuels, that become less available for ignition. In our work, rainfall influence is integrated into the model by using the mean annual precipitation from the period 1931-1960 (Fig. 7). 


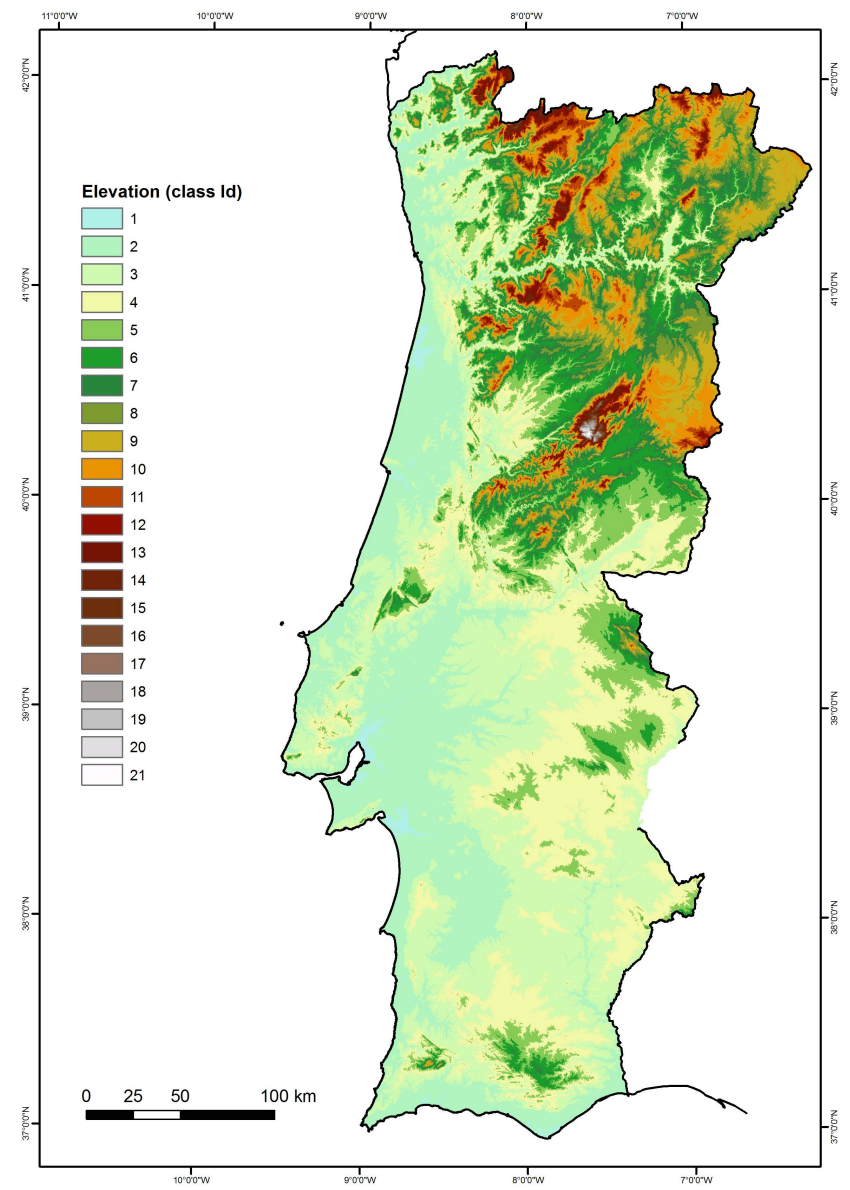

Fig. 4. Elevation map. Legend: class Id (see Table 1).

The rainfall annual average does not allow for a total assessment of the above-mentioned rationale, however, knowing how rainfall is distributed in Portugal, one can assume the spatial coincidence between the higher annual rainfall and the winter rainfall maxima, hence, confirming what Pereira et al. (2006) have pointed out.

In previous studies (Pereira and Santos, 2003), air temperature has been used as a variable for wildfire susceptibility assessment, assuming that regions with higher air temperatures are those of higher wildfire susceptibility. Ventura and Vasconcelos (2006) state that high temperatures and low humidity levels favour the drying of fuels. Having this assumption in mind, we chose to integrate air temperature in a different way. Whereas in previous studies, like Pereira and Santos (2003), it was integrated as the number of days with temperatures equal or above $25^{\circ} \mathrm{C}$, between May and September, we used the average number of days with minimum temperatures equal to, or above, $20^{\circ} \mathrm{C}$ (Fig. 8), for the period 1990-2007. Considering that it is during night time that wildfire suppression efforts are more likely to succeed, taking advantage of lower temperatures and higher air humidity, we assume that where there are

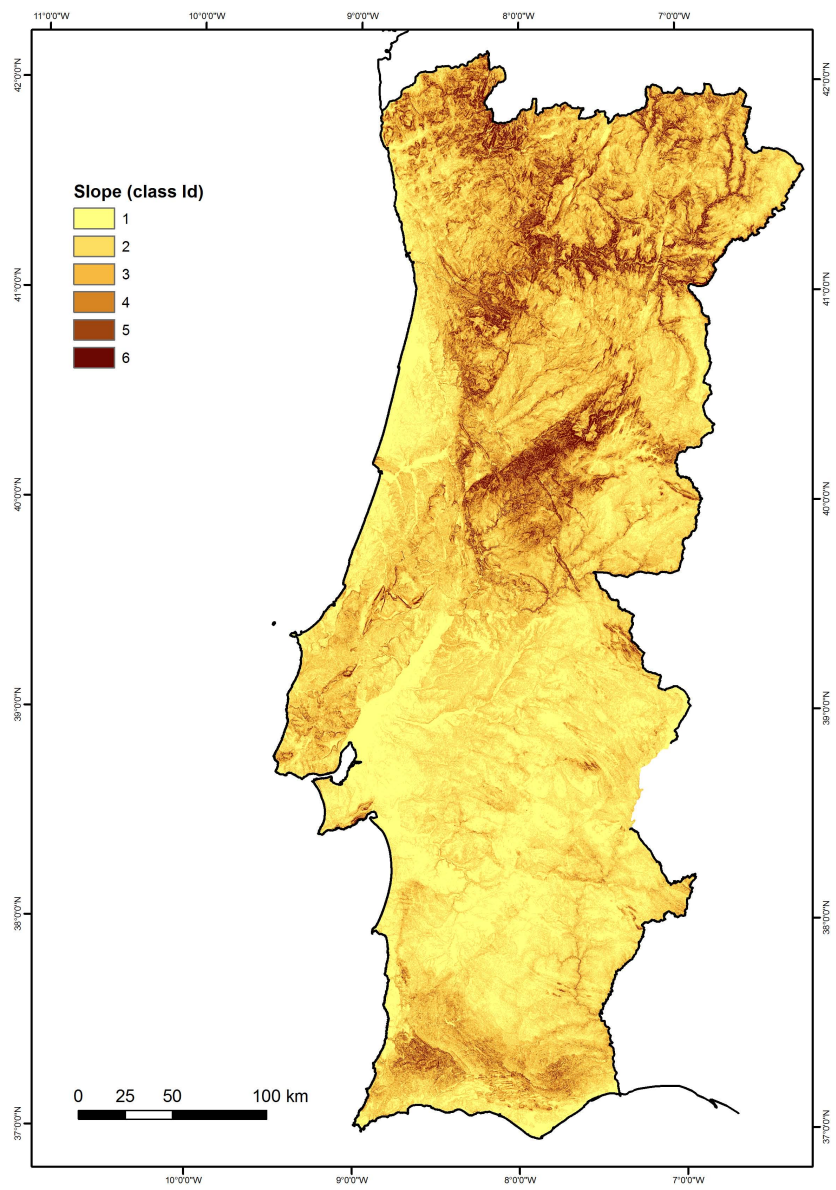

Fig. 5. Slope map. Legend: class Id (see Table 1).

more nights with temperatures equal or above $20^{\circ} \mathrm{C}$, wildfire susceptibility should be higher.

Past history of burnt areas enters into the model as a simple probability (Fig. 9), that allows us to read "every year, what is the probability of each ground unit to be affected by combustion?". This approach allows for discriminating, where fire is a recurring phenomenon rather than an unusual event. These wildfire records are also used to determine wildfire favourability for all other variables, as the past - from a mapped history of more than 30 years of wildfires - shows us how different classes of those variables behave under fire. Historical data is also a proxy for a factor that would, otherwise, be extremely difficult to integrate in the model: human behaviour. In fact, this factor is extremely important to understand wildfires in Portugal, because over 97\% of wildfires are linked with human causality (Beighley, 2009). In Table 1 , we present the legend and favourability scores for all variables, except for probability, for which no favourability score was computed. It should be noted that not all thematic layers have the same total number of pixels as a consequence of different criteria for definition of coastlines and inland water bodies. In the case of land cover, not considering levels 1, 


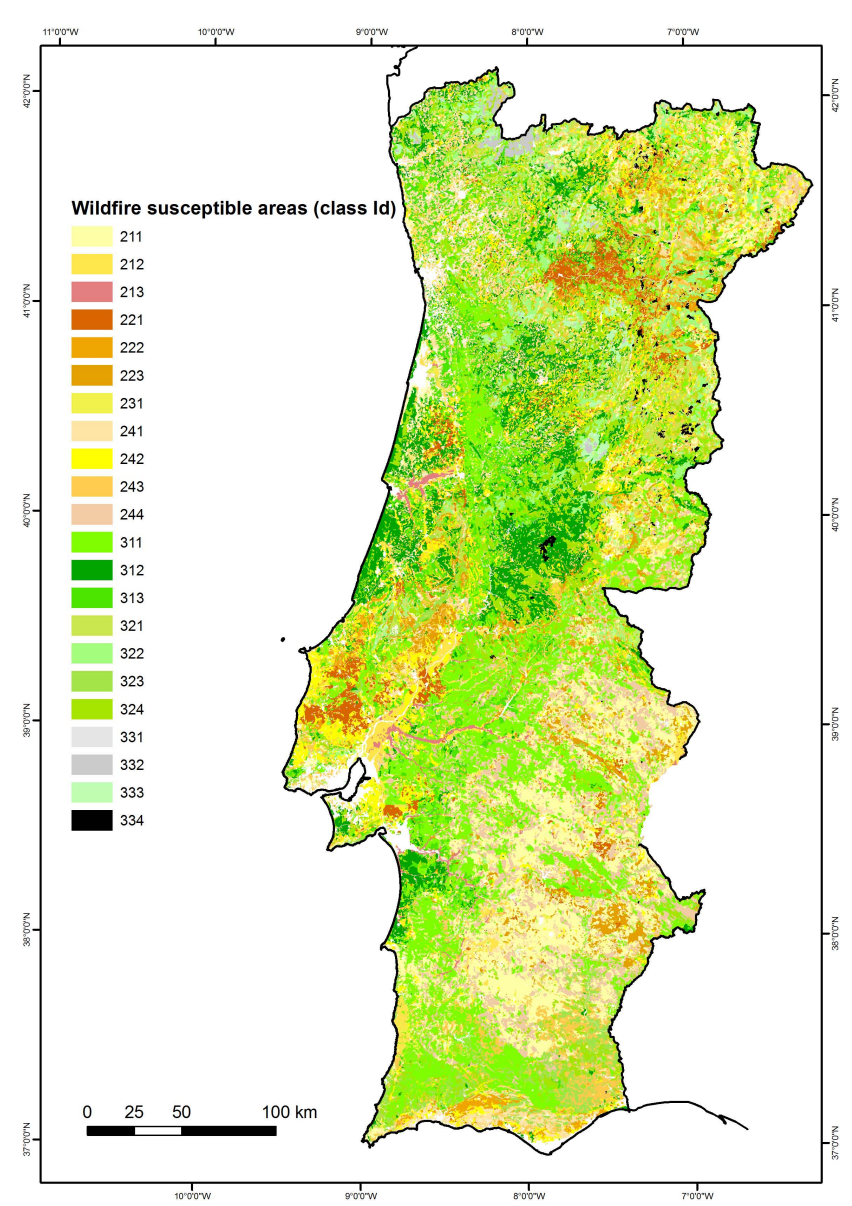

Fig. 6. Landcover map. Legend: class Id (see Table 1).

4 and 5 as previously stated, adds to this difference. We have chosen not to force all thematic layers to the same extent because the difference was small and in doing so we could bring erroneous data into the model. In all models, we used a subset of 20 years of burnt scars (1975-1994) to compute favourability scores, and the remaining set of 10 years (19952004) for the independent validation of susceptibility results (Fig. 10). It becomes clear that these thematic layers do not entirely share the same timeframe and this may be considered a drawback of our model. However, in a previous work, Verde (2008) had shown that the effectiveness of the model was not affected by combining land cover of the year 2000 with burnt scars of the period 1975-1994. In fact, that author has shown that, using land cover of the year 2000, the model has an overall better behaviour with older burnt scars (e.g. 1975-1984) than with a block comprising the year the land cover was created (1995-2004). In addition, climatologic data is assumed stable regarding their spatial distribution, and we expect annual rainfall and temperature patterns to remain reasonably unchanged in the medium-long term, taking into account the Portuguese climate, where the most annual rainfall occurs during winter time and the higher temperatures during the summer.

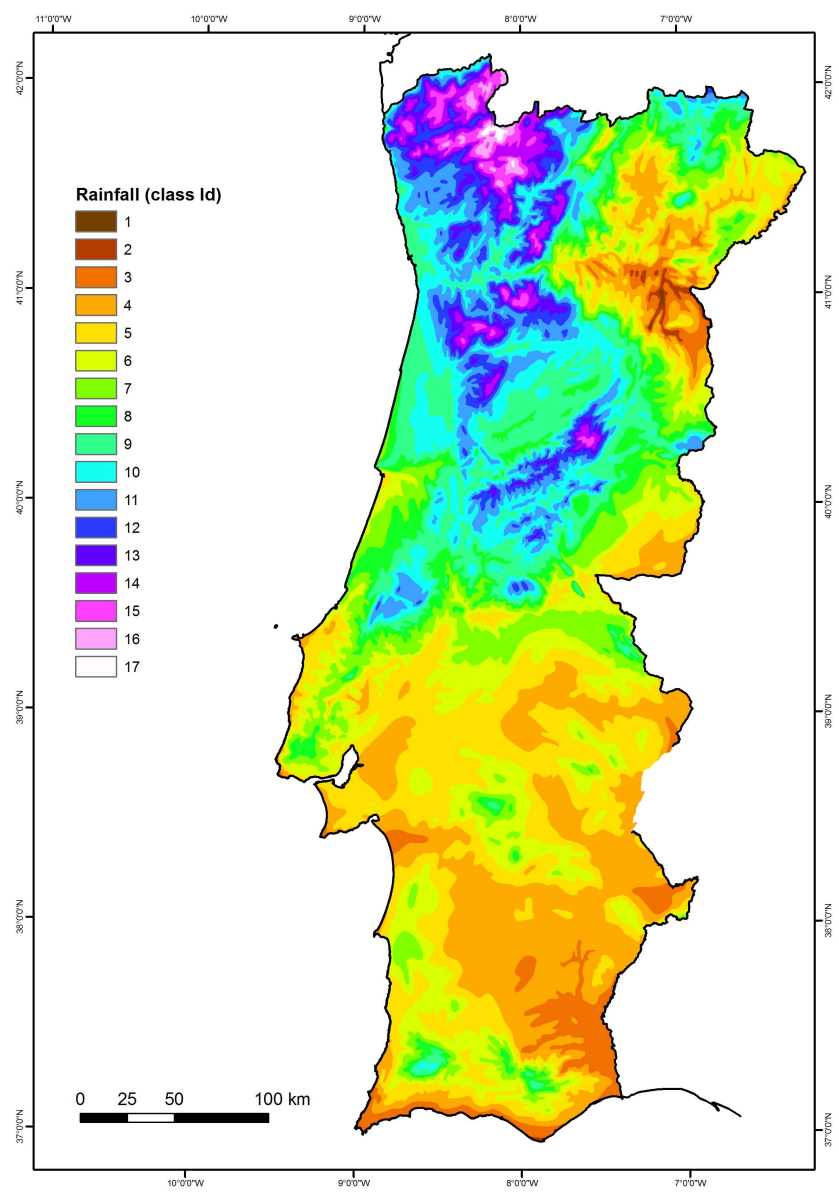

Fig. 7. Annual Rainfall map (based on Daveau et al., 1977). Legend: class Id (see Table 1).

\subsection{Integrating the variables}

We perform the wildfire susceptibility assessment based on the following assumptions: 1) the probability of occurrence of burnt areas can be quantitatively assessed by statistical relationships between past burnt areas and a spatial dataset; and 2) wildfires, assessed by their respective burnt areas, occur under conditions that can be characterised by the layers in the aforementioned spatial dataset, thus, considered as conditioning (or predisposal) variables, to be integrated in the prediction model.

Our work has been done in a GIS, with raster processing, after preparing and transforming vector data we had available. We used a $80-\mathrm{m}$ pixel size digital elevation model (source: http://www.fc.up.pt/pessoas/jagoncal/srtm/ srtm.htm) from which we derived the elevation and slope themes.

The rationale behind the use of the method used to weigh variable cases is beyond the scope of this paper, but it follows the work of Chung and Fabbri (1993) and Fabbri et al. (2002) regarding favourability scores. The basic equation 


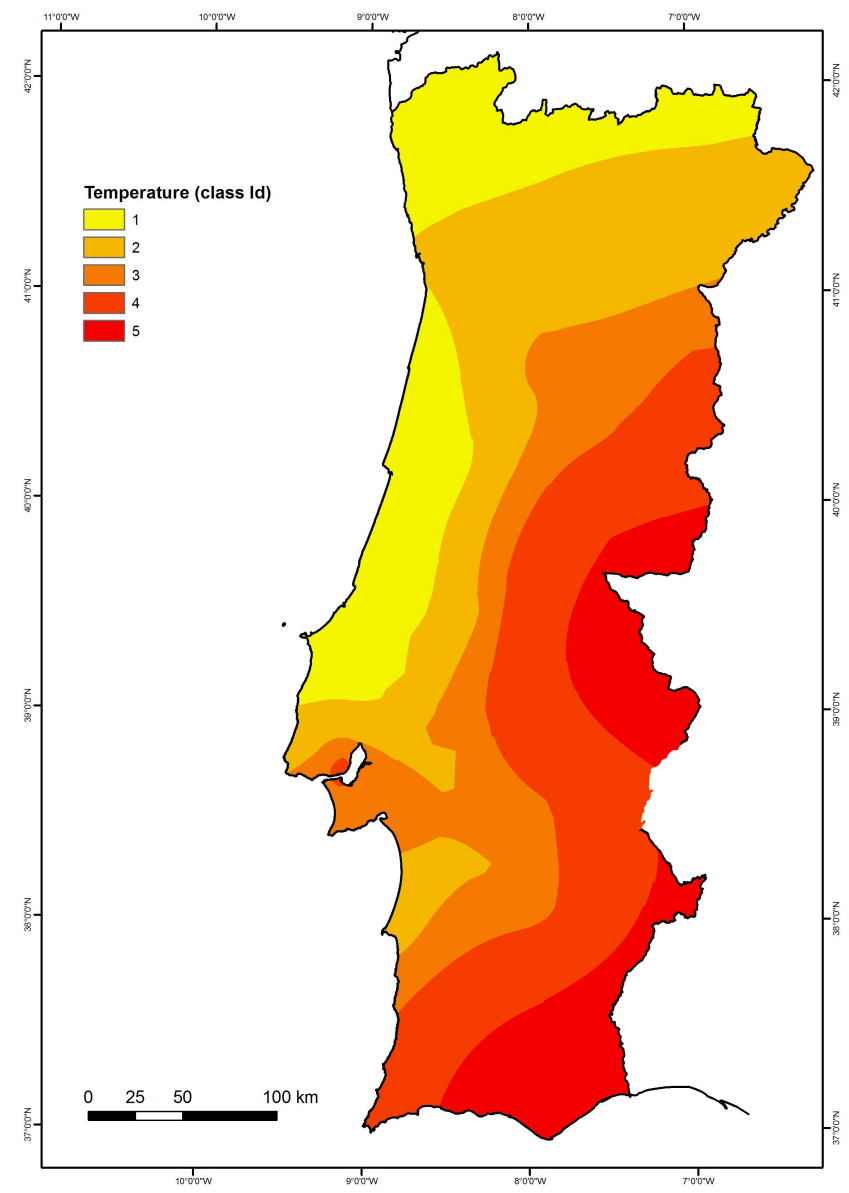

Fig. 8. Temperature map. Legend: class Id (see Table 1).

for favourability score calculation, for all variables, except probability, is:

$\mathrm{Sfx}=\frac{\mathrm{umAx}}{\Omega x} \cdot 100$

Where Sfx is the favourability score for class $x$, umAx is the total number of burnt units (or pixels) in class $x$, and $\Omega x$ is the total number of units of class $x$.

In addition, the transformation of historical data into a simple probability was made using Eq. (2):

$\mathrm{pa}=\frac{f}{N} \cdot 100$

Where pa is the probability (simple, not conditioned), $f$ is the number of times the pixel has been burnt, and $N$ the number of years. Due to the nature of our dataset, it is not possible for any pixel to have $f$ higher than 1 , therefore, pa can never exceed 1 (or, as per Eq. 2, 100). After all favourability scores and probability values have been calculated, we integrate the total set of variables using Eq. (3):

$\mathrm{UC}=\operatorname{pa} \cap \mathrm{Sf} 1 \cap \mathrm{Sf} 2 \cap \ldots \cap \mathrm{Sfn} \Leftrightarrow$

$\Leftrightarrow \mathrm{UCF}=F(\mathrm{pa}) \cdot F(\mathrm{Sf} 1) \cdot F(\mathrm{Sf} 2) \cdot F(\ldots) \cdot F(\mathrm{Sfn})$

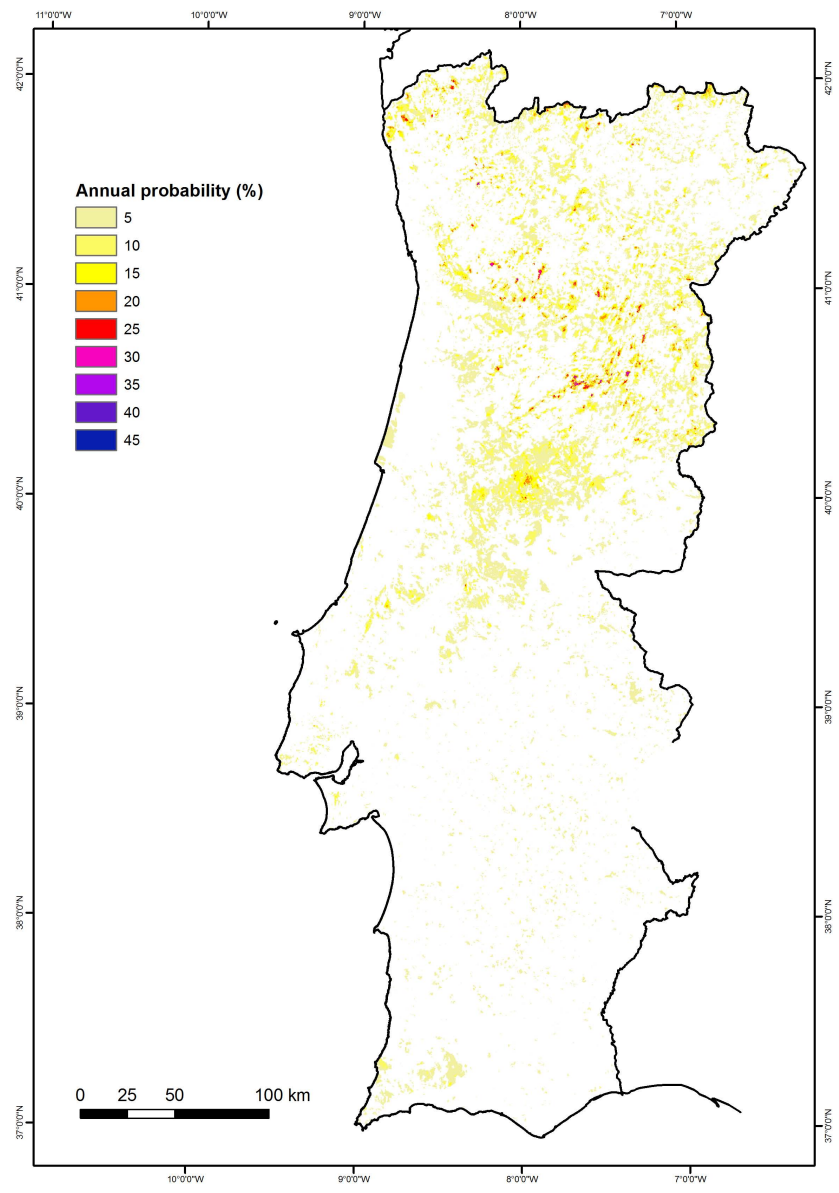

Fig. 9. Annual Probability of wildfire occurrence.

Where UC is a unique condition, UCF is the unique condition favourability value and $F$ is the favourability value of each class within each thematic layer.

The Unique Condition (UC) expresses all existing thematic layer combinations translated by the favourability value of each class in each thematic layer (pa, Sf1, Sf2,..., Sfn) as expressed in Eq. (3). The UC favourability value is calculated for each pixel and is given by the multiplication of the favourability score of each class variable present in the pixel (Eq. 3). It should be noted that wherever a favourability score computed zero, it was reclassified as the value one, thus, becoming neutral in the multiplication.

To identify each model, resulting from the integration of different variables, each layer is represented by a code, as follows: A - Elevation, D - Slope, C - Land cover, R Rainfall, T - Temperature, $\mathrm{P}$ - Probability. Combining these codes identifies which variables have been used, for example, a model identified by "ACD" is a model whose calculation took into account elevation, land cover and slope.

Unique condition favourabilities (UCF in Eq. 3) for each model, when ordered in descending order and crossed with burnt areas, allow computing two types of curve: success and 
Table 1. Thematic layers and favourability values of variables. The most significant results are highlighted in bold.

\begin{tabular}{|c|c|c|c|c|c|}
\hline $\begin{array}{l}\text { Thematic } \\
\text { layer class }\end{array}$ & $\begin{array}{l}\text { Class } \\
\text { ID }\end{array}$ & $\begin{array}{r}\text { Number of pixels } \\
\text { in the class }\end{array}$ & $\begin{array}{r}\text { Number of burnt pixels } \\
\text { within the class }\end{array}$ & $\begin{array}{r}\text { Favourability } \\
\text { value }\end{array}$ & $\begin{array}{c}\text { Data } \\
\text { capture }\end{array}$ \\
\hline \multicolumn{6}{|c|}{ Elevation (m) } \\
\hline 0 & 1 & 114515 & 240 & 0.0021 & \\
\hline $0-100$ & 2 & 2769360 & 103914 & 0.0375 & \\
\hline $100-200$ & 3 & 3102003 & 216481 & 0.0698 & \\
\hline $200-300$ & 4 & 2490516 & 237136 & 0.0952 & \\
\hline $300-400$ & 5 & 1384088 & 217162 & 0.1569 & \\
\hline $400-500$ & 6 & 951387 & 217120 & 0.2282 & \\
\hline $500-600$ & 7 & 774191 & 223624 & 0.2888 & \\
\hline $600-700$ & 8 & 732445 & 222151 & 0.3033 & \\
\hline $700-800$ & 9 & 702783 & 214079 & 0.3046 & \\
\hline 800-900 & 10 & 436979 & 160150 & 0.3665 & Derived \\
\hline 900-1000 & 11 & 221888 & 100843 & 0.4545 & from DEM \\
\hline $1000-1100$ & 12 & 112622 & 58780 & 0.5219 & (80-m pixel) \\
\hline $1100-1200$ & 13 & 59698 & 34392 & 0.5761 & \\
\hline $1200-1300$ & 14 & 31791 & 19637 & 0.6177 & \\
\hline $1300-1400$ & 15 & 14420 & 7160 & 0.4965 & \\
\hline $1400-1500$ & 16 & 7932 & 2240 & 0.2824 & \\
\hline $1500-1600$ & 17 & 4695 & 1110 & 0.2364 & \\
\hline $1600-1700$ & 18 & 3961 & 547 & 0.1381 & \\
\hline $1700-1800$ & 19 & 1744 & 258 & 0.1479 & \\
\hline 1800-1900 & 20 & 1574 & 28 & 0.0178 & \\
\hline 1900-2000 & 21 & 420 & 0 & 0.0000 & \\
\hline Total & & 13919012 & 2037052 & & \\
\hline \multicolumn{6}{|c|}{ Slope angle } \\
\hline $0-2^{\circ}$ & 1 & 3769671 & 270168 & 0.0717 & \\
\hline $2-5^{\circ}$ & 2 & 4620398 & 647943 & 0.1402 & Derived \\
\hline $5-10^{\circ}$ & 3 & 3113286 & 856590 & 0.2751 & from DEM \\
\hline $10-15^{\circ}$ & 4 & 1363989 & 553316 & 0.4057 & (80-m pixel) \\
\hline $15-20^{\circ}$ & 5 & 659408 & 315286 & 0.4781 & \\
\hline$>20^{\circ}$ & 6 & 392260 & 196724 & 0.5015 & \\
\hline Total & & 13919012 & 2840027 & & \\
\hline \multicolumn{6}{|c|}{ Land cover (wildfire susceptible areas) } \\
\hline Non-irrigated arable land & 211 & 1708124 & 82209 & 0.0481 & \\
\hline Permanently irrigated land & 212 & 304212 & 7269 & 0.0239 & \\
\hline Rice fields & 213 & 83543 & 662 & 0.0079 & \\
\hline Vineyards & 221 & 363891 & 8010 & 0.0220 & \\
\hline Fruit trees and berry plantations & 222 & 156557 & 5298 & 0.0338 & \\
\hline Olive groves & 223 & 422767 & 7772 & 0.0184 & \\
\hline Pastures & 231 & 58999 & 2444 & 0.0414 & \\
\hline $\begin{array}{l}\text { Annual crops associated with } \\
\text { permanent crops }\end{array}$ & 241 & 656927 & 10909 & 0.0166 & \\
\hline Complex cultivation patterns & 242 & 972839 & 17430 & 0.0179 & \\
\hline $\begin{array}{l}\text { Land principally occupied by } \\
\text { agriculture, with significant areas }\end{array}$ & & & & & Corine Land \\
\hline of natural vegetation & 243 & 1063543 & 75674 & 0.0712 & Cover 2000 \\
\hline Agro-forestry areas & 244 & 874533 & 20794 & 0.0238 & \\
\hline Broad-leaved forest & 311 & 1908393 & 212452 & 0.1113 & \\
\hline Coniferous forest & 312 & 1079951 & 214363 & 0.1985 & \\
\hline Mixed forest & 313 & 820553 & 145770 & 0.1776 & \\
\hline Natural grasslands & 321 & 289554 & 157757 & 0.5448 & \\
\hline Moors and heathland & 322 & 526757 & 290650 & 0.5518 & \\
\hline Schlerophyllous vegetation & 323 & 303814 & 46371 & 0.1526 & \\
\hline
\end{tabular}


Table 1. Continued.

\begin{tabular}{|c|c|c|c|c|c|}
\hline $\begin{array}{l}\text { Thematic } \\
\text { layer class }\end{array}$ & $\begin{array}{l}\text { Class } \\
\text { ID }\end{array}$ & $\begin{array}{r}\text { Number of pixels } \\
\text { in the class }\end{array}$ & $\begin{array}{r}\text { Number of burnt pixels } \\
\text { within the class }\end{array}$ & $\begin{array}{r}\text { Favourability } \\
\text { value }\end{array}$ & $\begin{array}{c}\text { Data } \\
\text { capture }\end{array}$ \\
\hline \multicolumn{6}{|c|}{ Land cover (wildfire susceptible areas) } \\
\hline Transitional woodland-shrub & 324 & 1505318 & 578481 & 0.3843 & \\
\hline Beaches, dunes, sands & 331 & 18868 & 456 & 0.0242 & \\
\hline Bare rocks & 332 & 69070 & 32018 & 0.4636 & \\
\hline Sparsely vegetated areas & 333 & 121568 & 79077 & 0.6505 & \\
\hline Burnt areas & 334 & 49378 & 27389 & 0.5547 & \\
\hline Total & & 13359159 & 2828548 & & \\
\hline \multicolumn{6}{|c|}{ Yearly average rainfall (mm) } \\
\hline $200-300$ & 1 & 3353 & 1488 & 0.4438 & \multirow{17}{*}{$\begin{array}{l}\text { From Daveau } \\
\text { et al. (1977) }\end{array}$} \\
\hline $300-400$ & 2 & 37445 & 16903 & 0.4514 & \\
\hline $400-500$ & 3 & 530578 & 52359 & 0.0987 & \\
\hline $500-600$ & 4 & 2274773 & 123320 & 0.0542 & \\
\hline $600-700$ & 5 & 2653299 & 163279 & 0.0615 & \\
\hline $700-800$ & 6 & 1893065 & 146436 & 0.0774 & \\
\hline 800-900 & 7 & 1247532 & 143681 & 0.1152 & \\
\hline $900-1000$ & 8 & 841013 & 154706 & 0.1840 & \\
\hline $1000-1200$ & 9 & 1329184 & 258192 & 0.1942 & \\
\hline $1200-1400$ & 10 & 1117460 & 288552 & 0.2582 & \\
\hline $1400-1600$ & 11 & 790464 & 267946 & 0.3390 & \\
\hline $1600-1800$ & 12 & 449731 & 148567 & 0.3303 & \\
\hline $1800-2000$ & 13 & 301067 & 100095 & 0.3325 & \\
\hline $2000-2500$ & 14 & 267007 & 88570 & 0.3317 & \\
\hline $2500-3000$ & 15 & 145103 & 53847 & 0.3711 & \\
\hline $3000-3500$ & 16 & 52601 & 21649 & 0.4116 & \\
\hline $3500-4000$ & 17 & 9002 & 3918 & 0.4352 & \\
\hline Total & & 13942677 & 2033508 & & \\
\hline \multicolumn{6}{|c|}{ Average number of days, per year, of minimum air temperature above $20^{\circ} \mathrm{C}$} \\
\hline $0-3 d$ & 1 & 2517498 & 395707 & 0.1572 & \multirow{6}{*}{$\begin{array}{l}\text { Meteorological } \\
\text { Institute }\end{array}$} \\
\hline $3-6 d$ & 2 & 3665182 & 720590 & 0.1966 & \\
\hline $6-9 d$ & 3 & 2561075 & 466648 & 0.1822 & \\
\hline $9-18 d$ & 4 & 3358875 & 383563 & 0.1142 & \\
\hline $18-36 \mathrm{~d}$ & 5 & 1816251 & 70544 & 0.0388 & \\
\hline Total & & 13918881 & 2037052 & & \\
\hline
\end{tabular}

prediction rate curves. The success rate curve results from the cross tabulation between the model results and the burnt areas used to build the model. Therefore, this curve is able to evaluate the degree of model fit. The prediction rate curve results from the cross tabulation between the model results and an independent set of burnt areas that was not used in the model, as referenced in Sect. 3.1. Hence, prediction rate curve can be used to predict the future behaviour of wildfires.

\subsection{Model results and validation}

The first susceptibility model run was the CDP, assuming wildfire susceptibility can be assessed through integration of fuel (land cover), slope and the historical pattern (derived from past burnt areas). This is a model of high success and prediction rates (Fig. 11; Tables 2 and 3): the $30 \%$ most susceptible territory accounts for over $90 \%$ of burnt areas contained in the model. As for the prediction, the same $30 \%$ of the territory only predicts correctly $71 \%$ of those "new" burnt areas, not considered in the model (1995-2004 sub-set).

On a second model run, another variable was added to the model: elevation. The ACDP model maintains high rates (Tables 2 and 3); however, keeping 30\% of the most susceptible territory as reference, the success rate is slightly lower, but the prediction rate is somewhat better than before. In Fig. 12, we plot those curves, keeping CDP curves for comparison. 


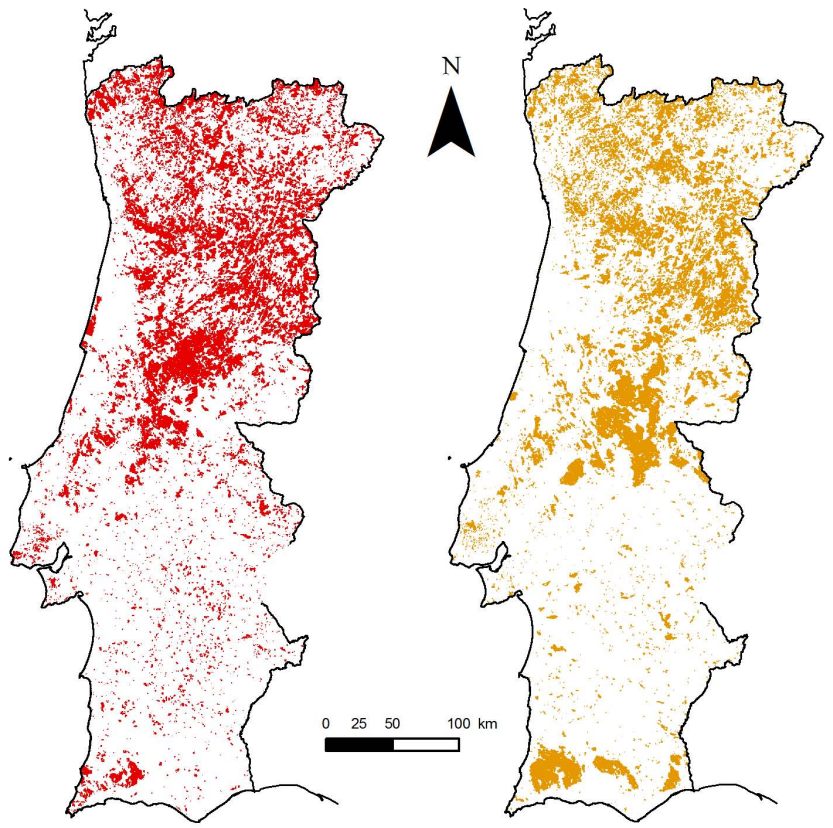

Model subset 1975-1994

Validation subset $1995-2004$

Fig. 10. Modelling and Validation wildfire data subsets.

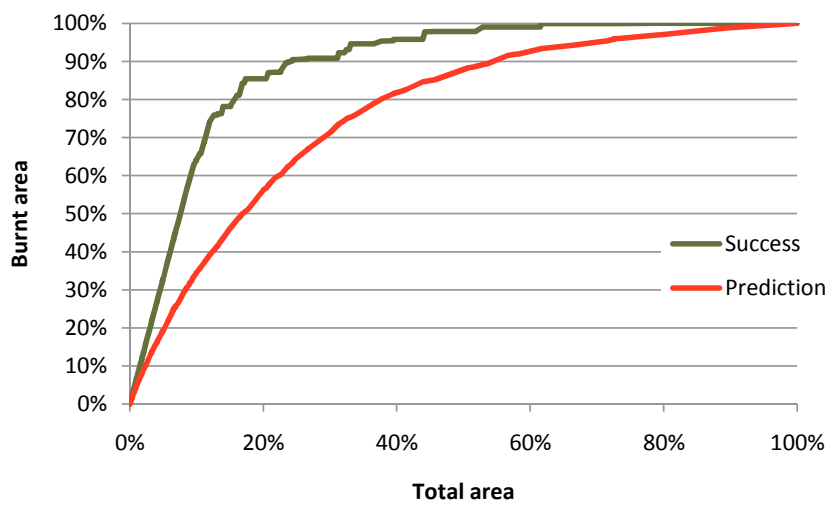

Fig. 11. Success rate and Prediction rate curves for the CDP model.

Next, to evaluate the impact of rainfall on susceptibility assessment, the rainfall layer was added to the model. The five variable model, ACDPR, shows the worse behaviour (Fig. 13). The prediction rate is similar to the previous model (ACDP), but the success rate is worse.

To complete this series of model runs, temperature was added to the model (Fig. 14). The six variable model, ACDPRT, has less satisfactory results, as both success and prediction rates are worse than any other previous model, as can be visually perceived in Fig. 14.

Although the general good quality of the wildfire susceptibility assessment, we wanted to evaluate the models response if burnt areas in the past (as mentioned earlier, transformed

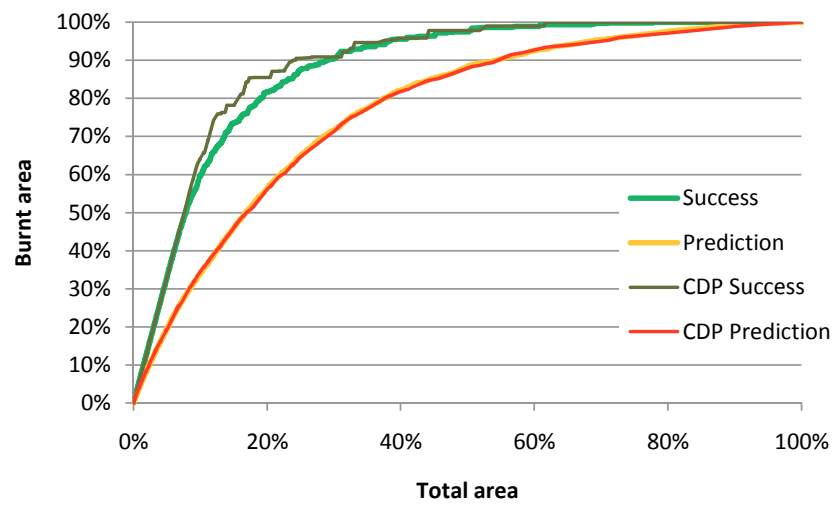

Fig. 12. Success rate and Prediction rate curves for the ACDP model.

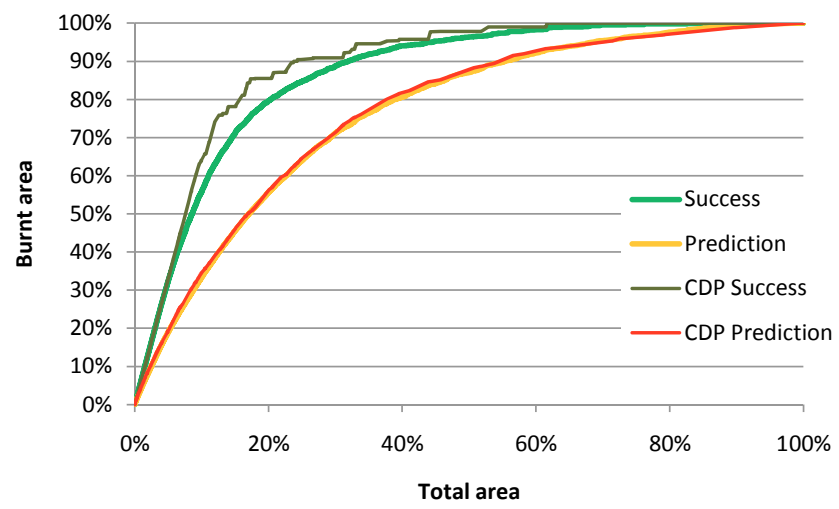

Fig. 13. Success and prediction curves for the ACDPR model.

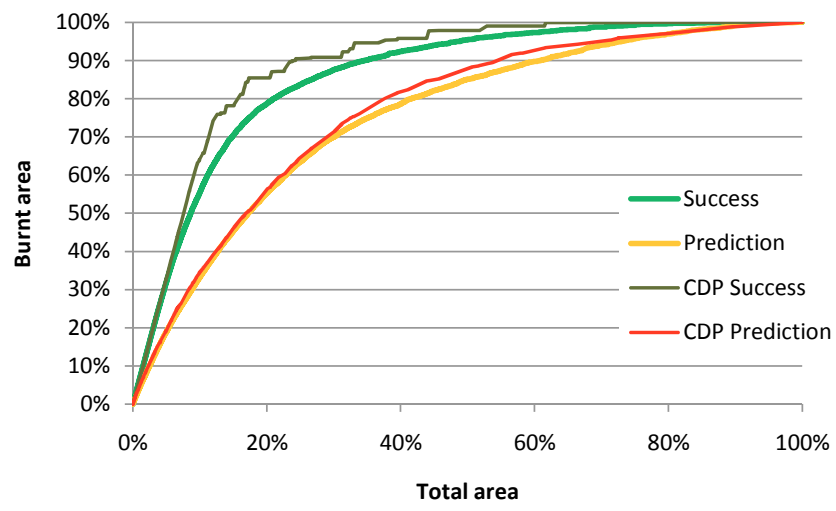

Fig. 14. Success rate and prediction rate curves for the ACDPRT model. 
Table 2. Success rates of susceptibility models. The most significant results are highlighted in bold.

\begin{tabular}{lccccccccc}
\hline Area & $10 \%$ & $20 \%$ & $30 \%$ & $40 \%$ & $50 \%$ & $60 \%$ & $70 \%$ & $80 \%$ & $90 \%$ \\
\hline CDP & $\mathbf{6 4 . 1 2 \%}$ & $\mathbf{8 5 . 4 6 \%}$ & $\mathbf{9 0 . 8 7 \%}$ & $\mathbf{9 5 . 7 7 \%}$ & $\mathbf{9 7 . 8 3 \%}$ & $\mathbf{9 9 . 0 0 \%}$ & $\mathbf{9 9 . 9 7 \%}$ & $\mathbf{1 0 0 \%}$ & $\mathbf{1 0 0 \%}$ \\
ACDP & $59.47 \%$ & $81.72 \%$ & $90.42 \%$ & $95.57 \%$ & $97.42 \%$ & $98.88 \%$ & $99.73 \%$ & $99.97 \%$ & $99.99 \%$ \\
ACDPR & $55.76 \%$ & $79.66 \%$ & $88.84 \%$ & $94.06 \%$ & $96.35 \%$ & $98.26 \%$ & $99.52 \%$ & $99.82 \%$ & $99.98 \%$ \\
ACDPRT & $55.59 \%$ & $79.12 \%$ & $88.60 \%$ & $93.55 \%$ & $95.73 \%$ & $97.44 \%$ & $98.99 \%$ & $99.77 \%$ & $99.97 \%$ \\
CD & $36.39 \%$ & $60.07 \%$ & $75.92 \%$ & $84.83 \%$ & $89.21 \%$ & $92.62 \%$ & $94.96 \%$ & $97.84 \%$ & $99.00 \%$ \\
ACD & $37.51 \%$ & $62.38 \%$ & $76.24 \%$ & $84.78 \%$ & $89.59 \%$ & $93.36 \%$ & $95.77 \%$ & $97.69 \%$ & $99.27 \%$ \\
ACDR & $36.90 \%$ & $62.25 \%$ & $77.50 \%$ & $85.22 \%$ & $90.00 \%$ & $93.25 \%$ & $95.50 \%$ & $97.36 \%$ & $99.00 \%$ \\
ACDRT & $36.78 \%$ & $62.47 \%$ & $78.36 \%$ & $85.75 \%$ & $90.19 \%$ & $93.25 \%$ & $95.09 \%$ & $97.01 \%$ & $98.82 \%$ \\
\hline
\end{tabular}

Table 3. Prediction rates of susceptibility models. The most significant results are highlighted in bold.

\begin{tabular}{lccccccccc}
\hline Area & $10 \%$ & $20 \%$ & $30 \%$ & $40 \%$ & $50 \%$ & $60 \%$ & $70 \%$ & $80 \%$ & $90 \%$ \\
\hline CDP & $\mathbf{3 4 . 5 2 \%}$ & $\mathbf{5 6 . 3 6 \%}$ & $71.31 \%$ & $81.77 \%$ & $87.87 \%$ & $\mathbf{9 2 . 6 8 \%}$ & $95.02 \%$ & $97.11 \%$ & $\mathbf{9 9 . 7 9 \%}$ \\
ACDP & $33.91 \%$ & $56.31 \%$ & $\mathbf{7 1 . 6 5 \%}$ & $\mathbf{8 2 . 0 8 \%}$ & $\mathbf{8 8 . 4 1 \%}$ & $92.53 \%$ & $95.40 \%$ & $97.55 \%$ & $99.23 \%$ \\
ACDPR & $33.37 \%$ & $55.65 \%$ & $71.14 \%$ & $80.63 \%$ & $87.06 \%$ & $92.21 \%$ & $\mathbf{9 5 . 4 2 \%}$ & $\mathbf{9 7 . 6 1 \%}$ & $99.32 \%$ \\
ACDPRT & $33.08 \%$ & $54.13 \%$ & $69.11 \%$ & $79.06 \%$ & $85.55 \%$ & $90.51 \%$ & $94.22 \%$ & $97.00 \%$ & $99.06 \%$ \\
CD & $30.48 \%$ & $53.29 \%$ & $70.12 \%$ & $80.15 \%$ & $87.04 \%$ & $92.39 \%$ & $94.74 \%$ & $96.96 \%$ & $98.81 \%$ \\
ACD & $31.04 \%$ & $53.99 \%$ & $70.36 \%$ & $81.01 \%$ & $87.81 \%$ & $92.25 \%$ & $95.24 \%$ & $97.50 \%$ & $99.22 \%$ \\
ACDR & $30.05 \%$ & $53.10 \%$ & $69.35 \%$ & $79.53 \%$ & $86.35 \%$ & $92.02 \%$ & $95.28 \%$ & $97.57 \%$ & $99.30 \%$ \\
ACDRT & $29.25 \%$ & $51.68 \%$ & $67.61 \%$ & $77.83 \%$ & $84.56 \%$ & $90.23 \%$ & $94.02 \%$ & $96.89 \%$ & $99.02 \%$ \\
\hline
\end{tabular}

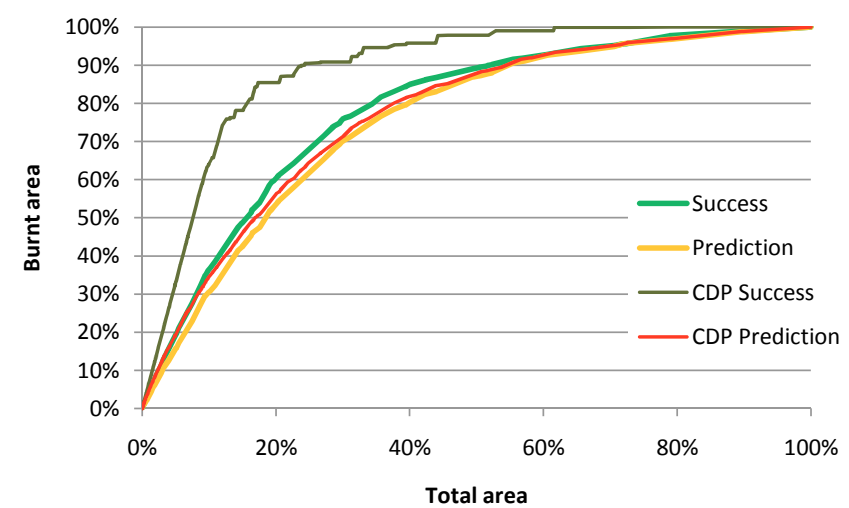

Fig. 15. Success rate and prediction rate curves for the CD model.

into a simple probability) were to be removed. Therefore, a second set of susceptibility models was performed without the $\mathrm{P}$ layer.

The first model run, in this series, was the $\mathrm{CD}$ model (Fig. 15). By comparison with the CDP model, when using only land cover and slopes, both success and prediction rates decrease in quality. Nevertheless, the similarity between the prediction rate curves of both models, CD and CDP (difference around just $1 \%$ ) is remarkable.

Figure 16 shows the differences between ACDP and ACD models. As in the previous case, the success rate is worse,

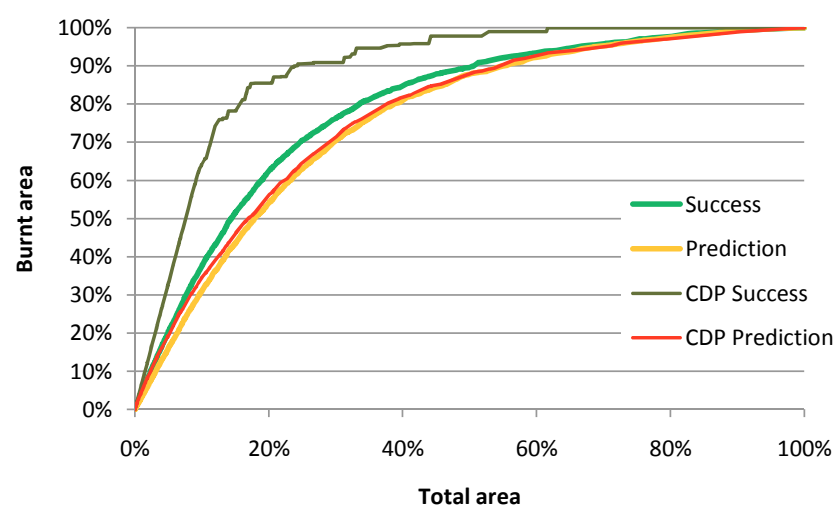

Fig. 16. Success rate and prediction rate curves for the ACD model.

but the prediction rate follows closely. In comparison to the previous model (CD), adding elevation resulted in a subtle gain, usually below $1 \%$, on both success and prediction rates.

Adding rainfall to this series of models (ACDR) generates similar results (Fig. 17). The success rate does increase slightly, but not always, and the prediction rate is below the previous ACD model up until $70 \%$ of the territory.

Last is the ACDRT model (Fig. 18), which adds temperature, allowing for a better success rate, but overall worse prediction rate than any other variable combination. 
Table 4. Areas under the curve for success and prediction rates, for the total set of susceptibility models.

\begin{tabular}{lllllllll}
\hline & CDP & ACDP & ACDPR & ACDPRT & CD & ACD & ACDR & ACDRT \\
\hline Success & $89.04 \%$ & $87.87 \%$ & $86.79 \%$ & $86.47 \%$ & $78.29 \%$ & $79.08 \%$ & $79.07 \%$ & $79.15 \%$ \\
Prediction & $76.87 \%$ & $77.06 \%$ & $76.60 \%$ & $75.50 \%$ & $75.61 \%$ & $76.05 \%$ & $75.57 \%$ & $74.39 \%$ \\
\hline
\end{tabular}

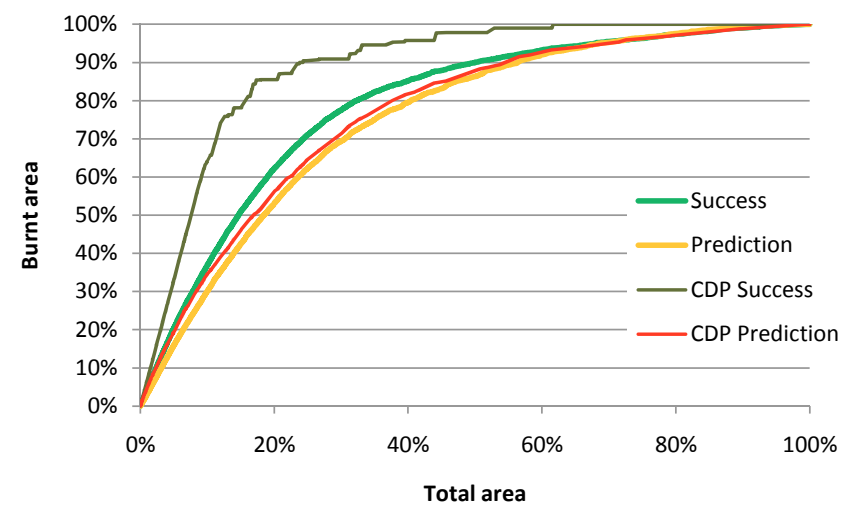

Fig. 17. Success rate and prediction rate curves for the ACDR model.

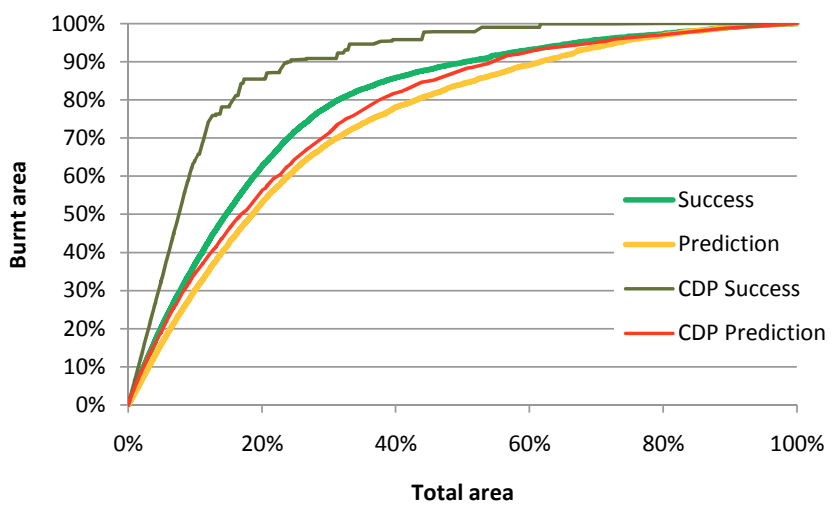

Fig. 18. Success rate and prediction rate curves for the ACDRT model.

For a better perception of the susceptibility models behaviour, we computed the area under the curve (AUC) for all models (Table 4). The CDP model is not the best one for prediction at all area marks. However, it addresses more of future burnt areas requiring less territory. Overall, the CDP model has the best predictive behaviour. Also, the AUCs clearly show that the CDP model has the best success rate.

As for prediction, CDP is only the second best susceptibility model, but it uses less variables, has the best success rate and, up to $20 \%$ of the territory (the highest susceptibility class), it predicts more burnt area than any other. Therefore, the CDP model was chosen as our reference wildfire susceptibility model. Because the prediction curve is so

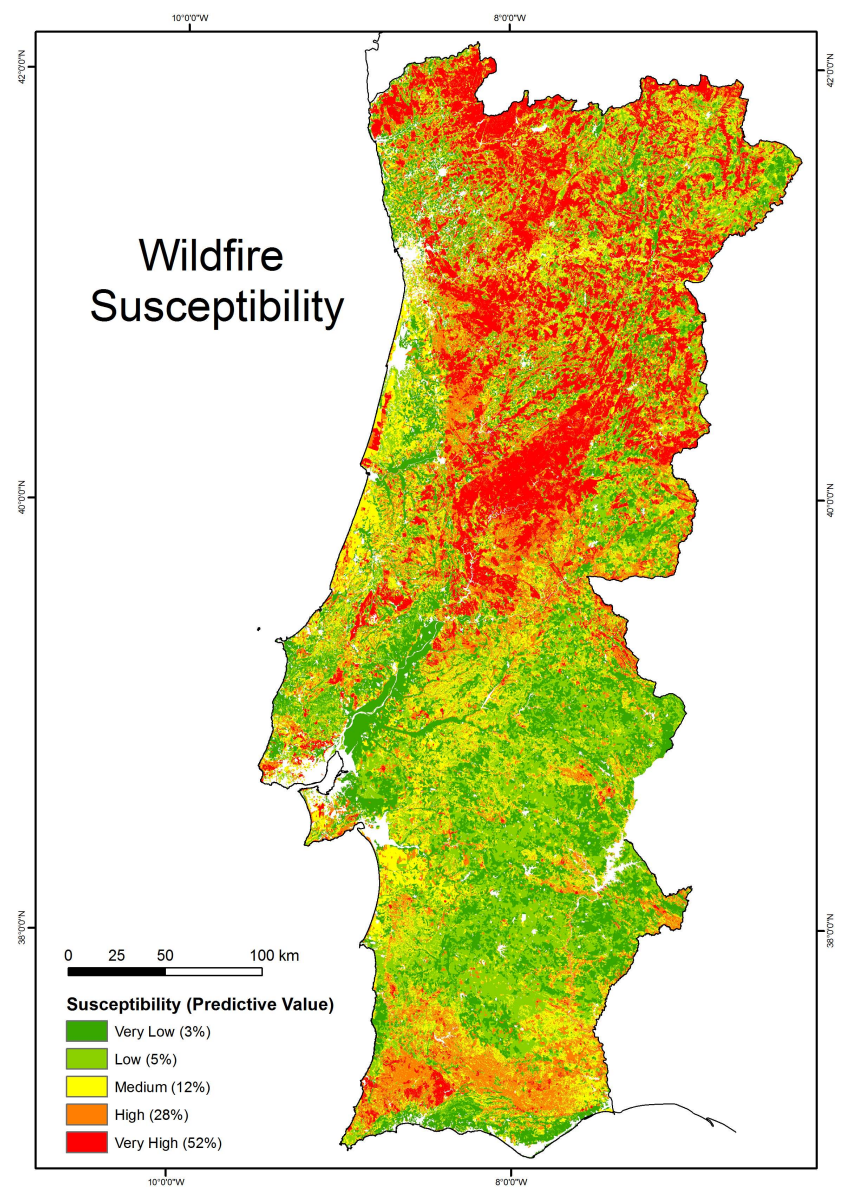

Fig. 19. Wildfire susceptibility in Portugal.

smooth, without any clear breaks that could guide classification, a quintile classification was chosen, with each class having around 20\% of susceptible territory. Figure 19 illustrates wildfire susceptibility in mainland Portugal. The prediction capacity ascribed to each susceptibility class was taken directly from the prediction rate curve of the CDP model. The meaning of the prediction values can be described as follows: $52 \%$ of the total area that will be burnt in the next future will be located in the susceptibility class "very high". On the contrary, the susceptibility class "very low" will include only $3 \%$ of the area to be affected by wildfires in the future. We have not yet explored the specific reasons behind model behaviour when adding or removing layers. It is possible 
Table 5. Hazard evaluation for wildfire susceptibility classes, for a scenario of 500000 ha burnt in a year.

\begin{tabular}{llll}
\hline $\begin{array}{l}\text { Susceptibility } \\
\text { class }\end{array}$ & $\begin{array}{l}\text { Area } \\
\text { (nr. of pixels, } \\
\text { pixel=80 m) }\end{array}$ & $\begin{array}{l}\text { Predictive } \\
\text { value }\end{array}$ & $\begin{array}{l}\text { Probability } \\
\text { per } \\
\text { pixel }\end{array}$ \\
\hline Very low & 2783096 & 0.03 & $0.85 \%$ \\
Low & 2780358 & 0.05 & $1.40 \%$ \\
Medium & 2758308 & 0.12 & $3.38 \%$ \\
High & 2634032 & 0.28 & $8.42 \%$ \\
Very high & 2401267 & 0.52 & $16.81 \%$ \\
\hline
\end{tabular}

that, due mainly to the human nature of Portuguese wildfires, variables not entirely related to the cause, but to the spread of fire, when stacked in the model, add noise that reduces its ability to accurately predict wildfire susceptibility. Many of the Portuguese wildfires are related to fuel management and landscape renewal or arsoning (AFN, 2009). Wildfires start and/or spread mainly where people want them to. It is, therefore, quite possible that the worst behaviour we get from the model, when adding more variables, simply demonstrates that their relevance, in this context, is not as high as it would be should the fire mainly be of natural origin.

\section{Hazard assessment}

The hazard map has the same appearance as the susceptibility map, but its classes are not subjective, they are probabilistic values, given by an underlying scenario of future burnt area.

For hazard assessment of a single pixel within a wildfire susceptibility class, we use the following equation (Zêzere et al., 2004):

$P=1-\left(1-\frac{\text { aaf }}{\mathrm{at}_{x}} \cdot \operatorname{vpred}_{x}\right)$

Where $P$ is the probability; aaf is the total area to be burnt in the considered scenario; at is the total area within the susceptibility class $x$; vpred is the predictive value for the susceptibility class $x$. Table 5 shows an example of a hazard calculation for each susceptibility class in a scenario of a total of 500000 ha burnt in a single year. It should be noted that the probabilities expressed in Table 5, are for each and every pixel within a class, that is, every pixel on the highest susceptibility class has a probability of ignition of $16.81 \%$.

\section{Conclusions}

The existing large number of studies on the subject of wildfires is an indicator of how important wildfires are and how they have motivated many investigators, due to the many aspects related to fire: social, economic, environmental and cultural. This has led to the development of many methods for assessing wildfire susceptibility, not only under static approaches, for medium- and long-term analysis, but also for decision critical applications: when wildfires are already spreading, taking into account current and local weather conditions.

We have shown that wildfire susceptibility and hazard can be assessed at a national scale using few variables, like past wildfire history, slope and land use. The relationships between fire, land use and slope allow us to identify those areas of higher susceptibility. Adding historical data provides a better understanding of where wildfires have a pattern and where recurrence places a problem. That is as relevant as wildfires in Portugal are mostly of human origin.

Using only three variables makes the model quick to implement and easy to process, while having a good compromise between simplicity and predictive capacity. We have demonstrated that adding more variables does not increase the model prediction capacity substantially.

We have also demonstrated that meteorological variables do not bring enough value to prediction rates, hence not offering a good justification for including them in the wildfire susceptibility model. Meteorological data is relevant on a daily basis, for wildfire forecast mostly when wildfires are already happening. However, it does not play a significant role on long-term susceptibility assessment and mapping.

Finally, hazard evaluation is very useful in preparation for worst case scenarios, and can be used as a method for determining the number of hectares for fuel management using techniques such as landscape mosaics and prescribed burning, determining optimal size for fuel management breaks, optimal size for forest roads, the location and density of water points for vehicles and airplanes, and for dimensioning of fuel management around buildings on urban/forest interfaces.

Acknowledgements. The authors want to thank the referees for their careful reading of the paper and for their useful suggestions, which led to a better presentation of this work's subject.

Edited by: R. Lasaponara

Reviewed by: S. Fuchs and three other anonymous referees

\section{References}

AFN: Incêndios Florestais 2008, Relatório Final, Autoridade Florestal Nacional, available at: http://www.afn. min-agricultura.pt/portal/dudf/informacoes/relatorios/2008/ incendios-florestais-2008-relatorio-final, (last access: 10 July 2009), 2007.

Amatulli, G., Peréz-Cabello, F., and de la Riva, J.: Mapping lightning/human-caused wildfires occurrence under ignition point location uncertainty, Ecol. Model., 200, 321-333, 2007.

Bachmann, A. and Allgöwer, B.: The need for a consistent wildfire risk terminology, in: Proceedings of the Joint Fire Science Conference and Workshop, Boise Idaho, 15-17 June 1999. 
Beighley, M.: Forest defense against fire in Portugal, situation and capability, The Forest, the Path to sustainable prosperity - International Seminar, Lisbon, 2 June 2009.

Chung, C. F. and Fabbri, A.: The representation of geoscience information for data integration, Nonrenewable Resources, 2(2), 122-138, 1993.

Chuvieco, E. and Congalton, R. G.: Application of remote sensing and geographic information systems to forest fire hazard mapping, Remote Sens. Environ., 29, 147-159, 1989.

Daveau, S., Coelho, C., Costa, V. G., and Carvalho, L. : Répartition et rythme des précipitations au Portugal, Lisboa, Memórias do Centro de Estudos Geográficos, 3, 192 pp., 1977.

Durão, R. M., Pereira, M. J., Branquinho, C., and Soares, A.: Assessing spatial uncertainty of the Portuguese fire risk through direct sequential simulation, Ecol. Model., 221, 27-33, 2010.

Fabbri, A., Chung, C. F., Napolitano, P., Remondo, J., and Zêzere, J. L.: Prediction rate functions of landslide susceptibility applied in the Iberian Peninsula, in: Risk Analysis III, Series: Management Information Systems, edited by: Brebbia, C. A., WIT Press, Southampton, Boston, 5, 703-718, 2002.

Ferreira de Castro, C., Serra, G., Parola, J., Reis, J., Lourenço, L., and Correia, S.: Combate a Incêndios Florestais, Manual de Formação Inicial do Bombeiro, 2nd edn., Escola Nacional de Bombeiros, Sintra, Portugal, 93 pp., 2003.

GFMC: Global Fire Monitoring Center: UN International Strategy for Disaster Reduction, http://www.fire.uni-freiburg.de/, last access: 12 January 2010.

GWFEWS: Global Wildland Fire Early Warning System, http: //www.fire.uni-freiburg.de/fwf/fwf.htm, last access: 15 January 2010.

Le Page, Y., Pereira, J. M. C., Trigo, R., da Camara, C., Oom, D., and Mota, B.: Global fire activity patterns (1996-2006) and climatic influence: an analysis using the World Fire Atlas, Atmos. Chem. Phys., 8, 1911-1924, 2008, http://www.atmos-chem-phys.net/8/1911/2008/.

Macedo, F. W. and Sardinha, A. M.: Fogos Florestais, 2nd edn., Publ. Ciência e Vida, Lisboa, I, 430 pp., 1993.

NOAA: National Oceanic and Atmospheric Administration, National Weather Service: Fire Weather, available at: http://radar. srh.noaa.gov/fire/, last access: 15 January 2010.
Pereira, J. M. C. P. and Santos, M. T.: Áreas Queimadas e Risco de Incêndio em Portugal, Direcção-Geral das Florestas, Lisboa, Portugal, 64 pp., 2003.

Pereira, M. G., Trigo, R. M., DaCamara, C. C., Pereira, J. M. C., and Leite, S. M.: Synoptic patterns associated with large summer forest fires in Portugal, Agr. Forest Meteorol., 129, 11-25, 2005.

Pereira, J. M. C. P, Carreiras, J., Silva, J., and Vasconcelos, M.: Alguns conceitos básicos sobre os fogos rurais em Portugal, in: Incêndios Florestais em Portugal, Caracterização, Impactes e Prevenção, ISAPress, Lisboa, Portugal, 133-161, 2006.

Trigo, R. M., Pereira, J. M. C., Pereira, M. G., Mota, B., Calado, M. T., DaCamara, C. C., and Santo, F. E.: The exceptional fire season of summer 2003 in Portugal, Int. J. Climatol., 26, 17411757, 2006.

UNDRO: Natural Disasters and Vulnerability Analysis, Report of Expert Group Meeting, Office of the United Nations Disaster Relief Coordinator, Geneva, 9-12 July 1979.

Varnes, D. J.: Landslide hazard zonation: a review of principles and practice, UNESCO, Paris, 1984.

Vasilakos, C., Kalabokidis, K., Hatzopoulos, J., Kallos, G., and Matsinos, Y.: Integrating new methods and tools in fire danger rating, Int. J. Wildland Fire, 16, 306-316, 2007.

Ventura, J. and Vasconcelos, M. J.: O fogo como processo físico-químico e ecológico, Incêndios Florestais em Portugal, Caracterização, Impactes e Prevenção, ISAPress, Lisboa, Portugal, 93-113, 2006.

Verde, J.: Wildfire Hazard Assessment, M.Sc. thesis, University of Lisbon, Portugal, 2008 (in Portuguese).

Viegas, X., Bovio, G., Ferreira, A., Nosenzo, A., and Bernard, S.: Comparative study of various methods of fire danger evaluation in Southern Europe, Int. J. Wildland Fire, 9(4), 235-246, 1999.

Viegas, D. X.: Modelação do comportamento do fogo, Incêndios Florestais em Portugal, Caracterização, Impactes e Prevenção, ISAPress, Lisboa, Portugal, 287-325, 2006.

Zêzere, J. L., Reis, E., Garcia, R., Oliveira, S., Rodrigues, M. L., Vieira, G., and Ferreira, A. B.: Integration of spatial and temporal data for the definition of different landslide hazard scenarios in the area north of Lisbon (Portugal), Nat. Hazards Earth Syst. Sci., 4, 133-146, 2004, http://www.nat-hazards-earth-syst-sci.net/4/133/2004/. 